\title{
What is new in ventilation strategies for the neonate?
}

\author{
Anne Greenough • Atul Sharma
}

Received: 13 March 2007 / Accepted: 8 May 2007 / Published online: 2 June 2007

(C) Springer-Verlag 2007

\begin{abstract}
A large number of ventilation strategies are now available for the neonate. This review has focused on new information, that is, studies published since 2000 and the implication of their results for current clinical practice. Meta-analysis of randomised trials has demonstrated that assist control and synchronous intermittent mandatory ventilation (SIMV) shortens the duration of ventilation only if started in the recovery rather than the early stage of respiratory disease. A recent randomised trial demonstrated pressure-regulated volume control ventilation may also have no advantages if started early. Weaning by SIMV with pressure support is better (reducing oxygen dependency) than SIMV alone. Meta-analysis of volume-targeted ventilation demonstrated significant reductions in the duration of ventilation and pneumothorax, but the trials were small and of different designs. Volume guarantee may provide more consistent blood gas control. The level of volume targeting appears to be crucial to the success of this technique. Meta-analysis of randomised trials of prophylactic high-frequency oscillation trials has shown a modest
\end{abstract}

Source of funding and grants: Atul Sharma is supported by the WellChild Trust.

\footnotetext{
A. Greenough $\cdot$ A. Sharma

Division of Asthma, Allergy and Lung Biology,

King's College London,

London, UK

A. Greenough $(\square)$

Children Nationwide Regional Neonatal Intensive Care Centre,

King's College Hospital,

4th floor, Golden Jubilee Wing,

London SE5 9PJ, UK

e-mail: anne.greenough@kcl.ac.uk
}

reduction in bronchopulmonary dysplasia. Randomised trials have failed to confirm the advantages of nasal continuous positive airway pressure (NCPAP) seen in various non-randomised studies; however, the randomised trials reported to date have been small. Inhaled nitric oxide (NO) does not improve the outcome of prematurely born infants with severe respiratory failure, but early low-dose prolonged iNO appears to have benefits that merit further testing. More randomised trials with long-term outcomes are required to identify the optimal ventilation strategy(ies) for the neonate.

Keywords Continuous positive airway pressure .

High-frequency oscillation · Patient triggered ventilation .

Ventilation · Prematurity
Abbreviations
A/C Assist/control
BPD Bronchopulmonary dysplasia
CPAP Continuous positive airway pressure
HFOV High-frequency oscillation ventilation
HHFNC Humidified high-flow nasal cannula
$\mathrm{ICH}$ Intracranial haemorrhage
iNO Inhaled nitric oxide
IPPV Intermittent positive pressure ventilation
MAP Mean airway pressure
PAV Proportional assist ventilation
PS Pressure support
PTV Patient trigger ventilation
PVL Periventricular leukomalacia
SIMV Synchronised intermittent mandatory ventilation
SNIPPV Synchronised nasal intermittent positive pres- sure ventilation
VG Volume guarantee
VTV Volume-targeted ventilation 


\section{Introduction}

A large number of ventilation strategies are now available for the neonate. The quality of evidence to support particular strategies, however, varies. This review has focused in particular on new information - that is, on the results of clinical studies published since 2000 - and discusses the implications of those results for current practice.

\section{Patient-triggered ventilation (PTV)}

PTV was reintroduced into neonatal intensive care in the 1980s, initially as assist/control (A/C, inflations triggered by every spontaneous breath that exceeded the critical trigger threshold) and synchronised intermittent mandatory ventilation (SIMV, only the preset number of inflations are triggered regardless of the infant's spontaneous respiratory rate).It was hoped that these ventilation modes would be more likely to promote synchrony between the infant and ventilator inflations and hence reduce airleaks and bronchopulmonary dysplasia (BPD). Unfortunately, meta-analysis of the randomised trials [16] demonstrated no significant differences in the rates of BPD, severe intracranial hemorrhage $(\mathrm{ICH})$, air leaks and mortality rates according to ventilation mode. PTV was associated with a shorter duration of ventilation, but this was only seen in infants recovering from respiratory distress rather than in those in the acute stages. Similarly, in a recent randomised trial [9] in which infants were randomised at less than $6 \mathrm{~h}$ of age, pressure-regulated volume control ventilation (a synchronised, pressure limited $\mathrm{A} / \mathrm{C}$ mode that sequentially varies the delivered pressure to approximate a target inspiratory tidal volume) compared to SIMV was not associated with an increased number of babies being extubated at 14 days.

Newer modes of triggered ventilation have now been introduced. During pressure support (PS), not only the initiation (as with $\mathrm{A} / \mathrm{C}$ and SIMV) but also the termination of ventilator inflation is determined by the infant's spontaneous respiratory efforts. PS may have advantages when used as a weaning mode [36]. In a randomised trial of 107 infants of birthweights between 500 and 1000 gm, weaning by SIMV plus PS compared to weaning by SIMV (reduction in rate) alone resulted in infants of birthweights between 700 and 1000 gm requiring significantly fewer days on supplemental oxygen (41 vs. 58 days) [36]. During proportional assist ventilation (PAV), the applied pressure is servocontrolled throughout each spontaneous breath, and the frequency, timing and rate of lung inflation are controlled by the patient. The applied pressure increases in proportion to the tidal volume and inspiratory flow generated by the patient, which can be enhanced to reduce the work of breathing. In a randomised study involving extremely low birthweight infants with evolving BPD, in which 4-h periods of different ventilation modes were compared, gas exchange was maintained at lower mean and peak pressures on PAV compared to $\mathrm{A} / \mathrm{C}$ or SIMV, but desaturations lasted longer on PAV [41]. These data [41] emphasise that backup conventional ventilation breaths must be provided during PAV to prevent apnoea-related desaturations [41]. A newly developed backup support $\left(\mathrm{SPO}_{2}\right.$-sensitive adaptive backup support) has been developed, and the use of this adaptive backup support with pulse oximetry-guided operation was shown to reduce the incidence and duration of oxygen desaturations [19].

\section{Volume-targeted ventilation (VTV)}

Many ventilator types designed for use in neonates can deliver a preset tidal volume; such systems are known as volumetargeted ventilation (VTV). There are different forms of VTV [28]. During volume controlled (VC) or volume support (VS) ventilation, the desired tidal volume is selected, and the duration of inflation depends on the time taken for the volume to be delivered, which is adjusted by changes in the inspiratory flow rate.

During volume guarantee (VG) ventilation, a preset expiratory tidal volume is selected, but the preset inspiratory time determines the duration of inflation. During volume limited ventilation, the pressure support for any inflation is aborted if the measured inspired tidal volume exceeds a preset upper limit. During volume control inflation there is a breath-by-breath servo-controlled flow, which is constant during inspiration so that the required volume is delivered over the set inspiratory time. Ventilator manufacturers have used different strategies to achieve VTV. The SLE 5000 and Bear Cub 750psv deliver targeted tidal or volume limited ventilation, the Draeger Babylog 8000 delivers VGV, the VIP BIRD and Avea deliver VC (or BS) ventilation and the Stephanie Paediatric ventilator delivers VC inspiration. In VTV, there are differences according to ventilator type in the delivered peak pressure, inflation time, airway pressure waveform and, hence, mean airway pressure [43]. In clinical studies, VG levels between 4 and $6 \mathrm{ml} / \mathrm{kg}$ have been used, but there is evidence to suggest that it is more appropriate to use the higher level. Greater lung inflammation was demonstrated when a volume of 3 rather than $5 \mathrm{ml} / \mathrm{kg}$ was used with SIPPV during the acute phase of respiratory distress syndrome (RDS) [25]. A level of 6 but not $4.5 \mathrm{ml} / \mathrm{kg}$ reduced the duration of hypoxemic episodes during SIMV in one study [34], and in another study, $6 \mathrm{ml} / \mathrm{kg}$ compared to 4 or $5 \mathrm{~m} / \mathrm{kg}$ was associated with the lowest work of breathing [42].

Meta-analysis of the results of four randomised trials [28] demonstrated that VTV was associated with significant 
reductions in the duration of ventilation and the rate of pneumothorax, but not death or BPD. The trials, however, were small; in total, only 178 infants were included in the meta-analysis. A further limitation was that different VTV modes were used in the four trials. In a subsequent randomised trial, infants with birthweights of 600-1500 gm supported by VC ventilation were compared to those supported by time-cycled pressure limited ventilation [45]; the former reached a predetermined success criterion earlier than the latter, with the difference reaching statistical significance only in babies with a birthweight less than $1000 \mathrm{gm}$. There were, however, no other advantages demonstrated. In another recent randomised study, VG with SIMV rather than SIMV alone was more effective in maintaining desirable carbon dioxide tensions in infants of greater than 25 weeks of gestational age, but was ineffective in more immature infants [7]. In very low birthweight (VLBW) infants with frequent hypoxaemic episodes, volume rather than pressure controlled SIMV was associated with less bradycardias, but it did not decrease the time spent at an oxygen saturation of less than $80 \%$ [20]. Evidence on whether the use of VG in combination with PS improves outcomes, particularly in terms of the effect on lung inflammation, is conflicting [10,26]. In one study, the only advantage of using VG with PS was that less blood gas monitoring was required [31].

\section{High-frequency oscillatory ventilation (HFOV)}

During HFOV, small tidal volumes are delivered at frequencies of between 8 and $15 \mathrm{~Hz}$. Certain oscillators display the volume delivered, but frequency can affect the accuracy of the displayed volume [24]. There have been at least 11 trials in which infants have been randomised to receive HFOV or standard ventilation techniques in the first $24 \mathrm{~h}$ after birth. Meta-analysis of their results [18] demonstrated that HFOV had no significant effect on mortality and only a modest reduction in BPD in terms of survivors at term; however, it had no statistically significant effect on short-term neurological abnormality, ICH or PVL. The three most recently reported randomised trials included in the meta-analysis yielded different results. Moriette et al. [29] reported that HFOV was associated with a trend towards an increase in severe ICH; the oscillator they employed has not been used in any of the other randomized trials. Courtney et al. [8] reported that HFOV reduced the combined outcome of BPD and death, but the randomized comparator group was supported by SIMV, which may have put them at a disadvantage as the work of breathing is increased at low SIMV rates. In the third trial [21] (United Kingdom Oscillation, UKOS trial), 799 infants below 29 weeks of gestation were randomised within $1 \mathrm{~h}$ of birth to HFOV or standard venti- lation techniques, and no benefits or disadvantages of HFOV were noted. In addition, the follow-up assessments of the UKOS survivors also demonstrated no significant differences in lung function results at 1 year of age [47] or in respiratory or neurodevelopmental outcome at 2 years of corrected age [27]. HFOV is also used to "rescue" infants with severe respiratory failure. Mean airway pressure (MAP) is increased in the hope of optimising lung volume and hence oxygenation. An initial improvement in oxygenation in response to HFOV, however, does not guarantee a normal neurodevelopmental outcome at 2 years in very prematurely born infants [12].

\section{Non-invasive respiratory support}

Continuous positive airway pressure (CPAP) can be delivered by a headbox, facemask, nasaopharyngeal or endotracheal tube, single or binasal prongs. Nasal CPAP is considered by many as a gentler form of respiratory support, but it does have adverse effects, including nasal trauma in between 20 and $32 \%$ of all infants. It had been suggested that nasal trauma might particularly be a problem with dual prongs, but randomised studies have demonstrated no significant differences in the incidence of trauma between binasal prongs, a nasaopharyngeal tube [5], binasal prongs or facemask [51]. The only significant relationship to trauma in one series was CPAP duration [51]. Newer forms of CPAP include variable flow and bubble CPAP. Variable CPAP has been associated with better lung recruitment than continuous flow CPAP and a lower work of breathing. Lung overdistension, however, may occur in infants with mild disease if variable flow CPAP levels greater than $6 \mathrm{~cm}$ $\mathrm{H}_{2} \mathrm{O}$ are used. During bubble CPAP, the pressure in the device is generated by a continuous flow of gas, with the distal end placed a set depth under water; the bubbles create pressure oscillations, which are transmitted back to the airway opening [33]. Clinical studies of bubble CPAP have yielded mixed results [30].

Early CPAP is now used in many centres in preference to early intubation and intermittent positive pressure ventilation (IPPV). Although early CPAP can be successful in very immature infants [4], it is more likely to fail in that group [1]. This was highlighted by a recent experience in Columbia [1]: whereas $95 \%$ of infants between 26 and 28 weeks were initially started on CPAP in the delivery room and $78 \%$ were successfully supported only by this technique, $69 \%$ of infants of $23-25$ weeks were treated initially with CPAP, but only $31 \%$ could be maintained on it [1]. In a nonrandomised comparison, the application of CPAP in the delivery suite in one centre compared to intubation in the other centre was associated with fewer infants requiring supplementary oxygen at 40 weeks post- 
menstrual age (P.A.) [48]. Randomised trials, however, have not confirmed the apparent benefits of CPAP reported in nonrandomised studies. Meta-analysis of two published randomised trials examining prophylactic CPAP commenced soon after birth demonstrated no significant differences in the use of mechanical ventilation or the incidence of BPD [46]. In addition, transient intubation for surfactant administration rather than nasal (n)CPAP was associated with fewer infants requiring mechanical ventilation and a lower concentration of supplementary oxygen [35]. Prophylactic CPAP (instituted within $30 \mathrm{~min}$ of birth) also appears not be more efficacious than rescue CPAP, which is applied when the inspired oxygen requirement is greater than $40 \%$, as no significant differences with regard to the need for surfactant treatment or mechanical ventilation were seen in a randomised trial including 230 infants of gestational ages between 29 and 31 weeks [37]. It has been suggested that the use of early nCPAP may improve neurological outcome, as fewer cases of intraventricular haemorrhage (IVH) and abnormal neurodevelopment were seen at 6 months of age following the systematic application of early nCPAP; however, the comparison was made to historical controls [50]. In a national Danish cohort study [17], comparison at age 5 years of all 269 survivors with a birthweight below $1000 \mathrm{gm}$ or a gestational age at birth of less than 28 weeks treated with early nCPAP revealed that these children have an intellectual development similar to that of a reference group of 76 term-born children [17].

Meta-analysis of the results of post-extubation randomised trials has demonstrated that CPAP significantly reduced the need for additional respiratory support (RR: 0.62, 0.49-0.77), but not the need for endotracheal intubation (RR: $0.93,0.72-1.19)$ or supplemental oxygen requirement at 28 days (RR: 1.00, 0.81-1.24) [11]. Indeed, in a subsequently reported prospective randomised trial involving 97 infants, $24 \mathrm{~h}$ of CPAP post-extubation compared to extubation directly into a headbox was not associated with a significant reduction in reventilation [32].

An alternative to the use of nCPAP is humidified high-flow nasal cannula (HHFNC) devices. The use of HHFNC has increased in many centres because of its ease of use and perceived improved tolerance with minimal nasal trauma compared to nCPAP [44]. There has, however, been concern regarding its imprecise regulation, the generation of pressure that might occur at higher flows - particularly in the smallest of infants - as well as a potential for increased work of breathing compared to that experience on nCPAP. In a small randomised trial [39], however, no increased work of breathing was demonstrated in infants less than $2 \mathrm{~kg}$ on HHFNC (3-5 Lpm) compared to $6 \mathrm{~cm} \mathrm{H}_{2} \mathrm{O}$ nCPAP. There have been concerns regarding increased Gram-negative bacteraemia, specifically $R$. picketti [6], when using the Vapotherm 2001, a device delivering high flow which, consequently, was recalled [44]. A positive association between nasal cannula CPAP and late-onset Gram-negative blood infections in VLBW infants has also been reported and attributed to nasal trauma [15]. The introduction of humidified high-flow nasal cannula (HHFNC) into two tertiary centres was associated with an increase (not significant) of Gram-negative bacteraemia [44]. In a randomised trial, however, HHFNC maintained a normal mucosa better than standard HFNC, but the relative impact of the devices on infection rates remains to be tested [49].

A variety of nasal ventilation modes, including IPPV, SIMV or HFOV delivered by nasal prongs are being used, and there is suggestion of benefit. Extubation immediately after surfactant administration to SNIPPV rather than continuing on conventional ventilation was associated with a decreased need for supplementary oxygen and shorter durations of intubation, parental nutrition and hospitalisation [38]. Similarly, in another study, extubation to SNIPPV rather than CPAP was associated with a shorter duration of supplementary oxygen and a lower incidence of BPD (73 vs. $40 \%$ ) [23]. Neither study [23, 38], however, was randomised. Older evidence is from anecdotal studies or trials with short-term outcomes; consequently, the true benefit (or the reverse) of these forms of support remains to be appropriately investigated.

\section{Inhaled nitric oxide (iNO)}

iNO, administered directly to the airway, is a selective pulmonary vasodilator used to treat hypoxemic respiratory failure associated with pulmonary hypertension of the newborn. Meta-analysis of the results of randomised trials has demonstrated that iNO reduces death or the need for extracorporeal membrane oxygenation (ECMO) in infants born at or near term, but the positive effect is the ECMO requirement [13]. Meta-analysis [3] of the results of seven trials in premature infants demonstrated that iNO had only short-term positive effects on oxygenation but no significant effects on mortality, BPD or ICH. In infants with severe respiratory failure, the use of iNO was associated with prolongation of intensive care and increased cost of care without clear beneficial effects [14]. In contrast, in one study [40], iNO was associated with a significant reduction in the combined outcome of death and BPD (RR: 0.76, $0.60-0.97$ ) and in grade 3 and 4 IVH (RR: 0.51, 0.270.97); sub-analysis demonstrated the advantages were seen in the infants with relatively mild disease. Recently, two further positive iNO studies have been reported; the results of both suggest that prolonged therapy with iNO may be efficacious. In one of these studies [22], although there was no overall reduction in death or BPD in infants with birthweights between 1000 and $1250 \mathrm{~g}$, low-dose (5 ppm) 
iNO given for 21 days or until extubation reduced the incidence of BPD by $50 \%$ and was associated with a lower rate of the combined outcome of $\mathrm{ICH}$, periventricular leukomalacia (PVL) and ventriculomegaly. In the second trial [2], iNO was associated with a significant increase in survival without BPD (43.9 vs. $36.8 \%$ ), with the minimum treatment exposure being 24 days. The infants who received iNO were discharged sooner and received supplemental oxygen for a shorter time. Post hoc analysis demonstrated that the positive effects were seen in infants enrolled at 7-14 days but not at 15-21 days, and they were restricted to infants with less severe lung disease. There are ongoing trials to determine whether early, low-dose prolonged iNO will improve the long-term pulmonary outcome of immature infants with relatively mild initial disease.

\section{References}

1. Ammari A, Suri M, Milasavljevic V, Sahni R, Bateman D, Sanocka U, Ruzal-Shapiro C, Wung JT, Polin RA (2005) Variables associated with the early failure of nasal CPAP in very low birth weight infants. J Pediatr 147:341-347

2. Ballard RA, Truog WE, Cnaan A, Martin RJ, Ballard PL, Merrill JD, Walsh MC, Durand DJ, Mayock DE, Eichenwald EC, Null DR, Hudak ML, Puri AR, Golombek SG, Courtney SE, Stewart DL, Welty SE, Phibbs RH, Hibbs AM, Luan X, Wadlinger SR, Asselin JM, Coburn CE; NO CLD Study Group (2006) Inhaled nitric oxide in preterm infants undergoing mechanical ventilation. N Engl J Med 355:343-353

3. Barrington KJ, Finer NN (2006) Inhaled nitric oxide for respiratory failure in preterm infants. Cochrane Database Syst Rev 3

4. Booth C, Premukumar MH, Yannoulis A, Thomson M, Harrison M, Edwards AD (2006) Sustainable use of continuous positive airway pressure in extremely preterm infants during the first week after delivery. Arch Dis Child Neonatal Ed 91:F398-F402

5. Buettiker V, Hug MI, Baenziger O, Meyer C, Frey B (2004) Advantages and disadvantages of different nasal CPAP systems in newborns. Intens Care Med 30:926-930

6. Centre for Disease Control Convention (2005) Ralstonia associated with vapotherm oxygen delivery service - United States. Morb Mortal Wkly Rep 54:1052-1054

7. Cheema IU, Sinha AK, Kempley ST, Ahluwalia JS (2007) Impact of volume guarantee ventilation on arterial carbon dioxide tension in newborn infants: a randomized controlled trial. Early Hum Dev 83:183-189

8. Courtney SE, Durand D J, Asselin J M, Hudak ML, Aschner JL, Shoemaker CT: Neonatal Ventilation Study Group (2002) High frequency oscillatory ventilation versus conventional mechanical ventilation for very low birthweight infants. $\mathrm{N}$ Engl J Med 347:643-652

9. D'Angio CT, Chess PR, Kovacs SJ, Sinkin RA, Phelps DL, Kendig JW, Myers GJ, Reubens L, Ryan RM (2005) Pressureregulated volume control ventilation versus synchronized intermittent mandatory ventilation for very low birthweight infants. Arch Pediatr Adolesc Med 159:868-875

10. Dani C, Bertini G, Pezzati M, Filippi L, Pratesi S, Caviglioli C, Rubaltelli FF (2006) Effects of pressure support ventilation plus volume guarantee vs. high-frequency oscillatory ventilation on lung inflammation in preterm infants. Pediatr Pulmonol 41:242-249

11. Davis PG, Henderson-Smart DJ (2006) Nasal continuous positive airways pressure immediately after extubation for preventing morbidity in preterm infants. Cochrane Database System Rev 3

12. Dimitriou G, Greenough A, Broomfield D, Morton M (2002) Rescue high frequency oscillation, hypocarbia and neurodevelopmental outcome in preterm infants. Early Hum Dev 66:133-141

13. Finer NN, Barrington KJ (2005) Nitric oxide for respiratory failure in infants born at or near term (Cochrane Review). Cochrane Database Syst Rev 3 (Update software, Oxford)

14. Field D, Elbourne A, Truesdale R, Grieve R, Hardy P, Fenton AC, Subhedar N, Ahluwalia J, Halliday HL, Stocks J, Tomlin K, Normand $\mathrm{C}$ and on behalf of the INNOVO Trial Collaborating Group (2005) Neonatal ventilation with inhaled nitric oxide versus ventilatory support without inhaled nitric oxide for Preterm infants with severe respiratory failure: the INNOVO multicentre randomised controlled trial (ISRCTN 17821339). Pediatrics 115:926-936

15. Graham III PL, Begg MD, Larson E, Della-Latta P, Allen A, Saiman L (2006) Risk factors for late onset gram-negative sepsis in low birthweight infants hospitalized in the neonatal intensive care unit. Pediatr Infect Dis J 25:113-117

16. Greenough A, Milner A D, Dimitriou G (2004) Synchronized ventilation (Cochrane review).Cochrane Database Syst Rev 3 (Update Software Oxford)

17. Hansen BM, Hoff B, Greisen G, Mortensen EL, Danish ETFOL Study Group (2004) Early nasal continuous positive airway pressure in a cohort of the smallest infants in Denmark: neurodevelopmental outcome at five years of age. Acta Paediatr 93:190-195

18. Henderson-Smart D J, Bhuta T, Cools F, Offringa M (2005) Elective high frequency oscillatory ventilation versus conventional ventilation for acute pulmonary dysfunction in preterm infants (Cochrane review). Cochrane Database Syst Rev 2007:1. (DOI: 10.1002/14651858.CD000104)

19. Herber-Jonat S, Rieger-Fackeldey E, Hummler H, Schulze A (2006) Adaptive mechanical backup ventilation for preterm infants on respiratory assist modes - a pilot study. Intens Care Med 32:302-308

20. Hummler HD, Engelmann A, Pohlandt F, Franz AR (2006) Volume controlled intermittent mandatory ventilation in preterm infants with hypoxemic episodes. Intens Care Med 32:577-584

21. Johnson AH, Peacock JL, Greenough A, Marlow N, Limb ES, Marston L, Calvert SA: for the United Kingdom Oscillation Study Group (2002) High frequency oscillatory ventilation for the prevention of chronic lung disease of prematurity. N Engl J Med 347:633-642

22. Kinsella JP, Cutter GR, Walsh WF, Gerstmann DR, Bose CL, Hart C, Sekar KC, Auten RL, Bhutani VK, Gerdes JS, George TN, Southgate WM, Carriedo H, Couser RJ, Mammel MC, Hall DC, Pappagallo M, Sardesai S, Strain JD, Baier M, Abman SH (2006) Early inhaled nitric oxide therapy in premature newborns with respiratory failure. N Engl J Med 355:354-364

23. Kulkarni A, Ehrenkranz RA, Bhandari V (2006) Effect of introduction of synchronized nasal intermittent positive-pressure ventilation in a neonatal intensive care unit on bronchopulmonary dysplasia and growth in preterm infants. Am J Perinatol 23:233-240

24. Leipala J, Iwasaki S, Milner AD, Greenough A (2004) Accuracy of the volume and pressure displays of high frequency oscillators. Arch Dis Child Fetal Neonatal Ed 24:731-733

25. Lista G, Castoldi F, Fontana P, Reali R, Reggiani A, Bianchi S, Compagnoni G (2006) Lung inflammation in preterm infants with respiratory distress syndrome: effects of ventilation with different tidal volumes. Pediatr Pulmonol 41:357-363

26. Lista G, Colnaghi M, Castolidi F, Condo V, Reali R, Compagnoni G, Mosca F (2004) Impact of targeted volume ventilation on lung 
inflammatory response in preterm infants with respiratory distress syndrome (RDS). Ped Pulmonol 37:510-514

27. Marlow N, Peacock J, Greenough A, Marston L, Limb ES, Johson $\mathrm{AH}$, Calvert S (2006) Randomised trial of high frequency oscillatory ventilation or conventional ventilation in babies of 28 weeks or less gestational age: respiratory and neurological outcomes at two years. Arch Dis Child Fetal Neonatal Ed 91:F320-F326

28. McCallion N, Davis PG, Morley CJ (2005) Volume targeted versus pressure limited ventilation in the neonate. Cochrane Database Syst Rev (DOI 10.1002/14651858: CD003666 pub 2)

29. Moriette G, Paris-Llado J, Walti H, Escande B, Magny JF, Cambonie G Thiriez G, Cantagrel S, Lacaze-Masmonteil T, Storme L, Blanc T, Liet JM, Andre C, Salanave B, Breart G (2001) Prospective randomized multicentre comparison of high frequency oscillatory ventilation and conventional ventilation in preterm infants less than 30 weeks with respiratory distress syndrome. Pediatrics 107:363-372

30. Morley CJ, Lau R, De Paoli A, Davis PG (2005) Nasal continuous positive airway pressure: does bubbling improve gas exchange. Arch Dis Child Fetal Neonatal Ed 90:343-344

31. Nafday SM, Green RS, Lin J, Brion LP, Ochshorn I, Holzman IR (2005) Is there an advantage of using pressure support ventilation with volume guarantee in the initial management of premature infants with respiratory distress syndrome? A pilot study. J Perinatol 25:193-197

32. Peake M, Dillon P, Shaw NJ (2005) Randomised trial of continuous positive airways pressure to prevent reventilation in preterm infants. Pediatr Pulmnol 39:247-250

33. Pillow J, Travadi JN (2005) Bubble CPAP: is the noise important? An in vitro study. Pediatr Res 57:826-830

34. Polimeni V, Claure N, D'Ugard C, Bancalari E (2006) Effects of volume-targeted synchronized intermittent mandatory ventilation on spontaneous episodes of hypoxemia in preterm infants. Biol Neonate 89:50-55

35. Reininger A, Khalak R, Kendig JW, Ryan RM, Stevens TP, Reubens L, D'Angio CT (2005) Surfactant administration by transient intubation in infants 29 to 35 weeks' gestation with respiratory distress syndrome decreases the likelihood of later mechanical ventilation: a randomised controlled trial. J Perinatol 25:703-708

36. Reyes ZC, Claure N, Tauscher MK, D'Ugard C, Vanbuskirk S, Bancalari E (2006) Randomised, controlled trial comparing synchronised intermittent mandatory ventilation and synchronised intermittent mandatory ventilation plus pressure support in preterm infants. Pediatrics 118:1409-1417

37. Sandri F, Ancora G, Lanzoni A, Taliabue P, Colnaghi M, Ventura ML, Rinaldi M, Mondello I, Gancia P, Salvioli GP, Orzalesi M, Mosca F (2004) Prophylactic nasal continuous positive airways pressure in newborns of 28-31 weeks gestation: multicentre randomized controlled trial. Arch Dis Child Fetal Neonatal Ed 89:F394-F398

38. Santin R, Brodsky N, Bhandari V (2004) A prospective observational pilot study of synchronized nasal intermittent positive pressure ventilation (SNIPPV) as a primary mode of ventilation in infants $>$ or $=28$ weeks with respiratory distress syndrome (RDS). J Perinatol 24:487-493

39. Saslow JG, Aghai ZH, Nakhla TA, Hart JJ, Lawrysh R, Stahl GE, Pyon KH (2006) Work of breathing using high flow nasal cannula in preterm infants. J Perinatol 26:476-480

40. Schreiber MD, Gin-Mestan K, Marks JD, Huo D, Lee G, Srisuparp P (2003) Inhaled nitric oxide in premature infants with the respiratory distress syndrome. N Engl J Med 349:2099-2107

41. Schulze A, Rieger-Fackeldey E, Gerhardt T, Claure N, Everett R, Bancalari E (2007) Randomised crossover comparison of proportional assist ventilation and patient triggered ventilation in extremely low birthweight infants with evolving chronic lung disease. Neonatology 92:1-7

42. Sharma A, Rafferty G, Milner A, Greenough A (2006) Volume guarantee level and work of breathing during neonatal ventilation. Eur Resp J 28:P2833-P491S

43. Sharma A, Sylvester K, Milner AD, Greenough A (2007) Performance of neonatal ventilators in volume guarantee mode. Acta Paediatr 96:176-180

44. Shoemaker MT, Pierce MR, Yoder BA, DiGeronimo RJ (2007) High flow nasal cannula versus nasal CPAP for neonatal respiratory disease: a retrospective study. J Perinatol 27:85-91

45. Singh J, Sinha SK, Clarke P, Bryne S, Donn SM (2006) Mechanical ventilation of very low birth weight infants: is volume or pressure a better target variable? J Pediatr 149:308-313

46. Subramaniam P, Henderson-Smart D, Davis PJ (2005) Prophylactic nasal continuous positive airway pressure for preventing morbidity and mortality in very preterm infants. Cochrane Database Syst Rev 3 (Update Software, Oxford)

47. Thomas M, Rafferty G, Limb E, Peacock JL, Calvert SA, Marlow N, Milner AD, Greenough A (2004) Pulmonary function at follow-up of very preterm infants form the UK oscillation study. Am J Resp Crit Care Med 169:868-872

48. Vanpee M, Walfridsson U, Katz-Salamon M, Zupancic JA, Pusley D, Jonsson B (2007) Resusucitation and ventilation strategies for extremely low birthweight infants: a comparison study between two neonatal centres in Boston and Stockholm. Acta Paediatr 96:6-10

49. Woodhead DD, Lambert DK, Clark JM, Chistensen RD (2006) Comparing two methods of delivering high flow gas therapy by nasal cannula following endotracheal extubation: a prospective randomized masked crossover trial. J Perinatol 26:481-485

50. Wintermark P, Tolsa JF, Van Melle G, Forcada-Guex M, Moessinger AC (2007) Long term outcome of preterm infants treated with nasal continuous positive airway pressure. Eur J Pediatr 166:473-483

51. Yong SC, Chen SJ, Boo NY (2005) Incidence of nasal trauma associated with nasal prong versus nasal mask during continuous positive airway pressure treatment in very low birthweight infants: a randomised control study. Arch Dis Child Fetal Neonatal Ed 90: F480-F483 